\title{
The Efficiency of the Education System and the Social Welfare: State of Correlation and Channels of Impact
}

\author{
Mostéfaoui Sofiane, Yousfat Ali \\ Department of Management Sciences, University of Adrar, Adrar, Algeria \\ Email address: \\ dr.yousfatali@gmail.com (Y. Ali) \\ ${ }^{*}$ Corresponding author
}

\section{To cite this article:}

Mosteffaoui Sofiane, Yousfat Ali. The Efficiency of the Education System and the Social Welfare: State of Correlation and Channels of Impact. European Business \& Management. Vol. 3, No. 2, 2017, pp. 16-20. doi: 10.11648/j.ebm.20170302.11

Received: February 3, 2017; Accepted: March 6, 2017; Published: March 21, 2017

\begin{abstract}
The social welfare as a concept describes a case in which a society enjoys both the micro and the macro wellbeing of its individuals. The former means the capability of persons to fulfill their different needs according to the hierarchy of Maslow pyramid. The latter underpins the extent to which these individuals are generally satisfied in their private and societal concerns. This paper attempts to highlight the efficiency of the education system in fulfilling the personal and common needs of people living in a society.
\end{abstract}

Keywords: Society, Education System, Efficiency

\section{The Education System and the Knowledge Structure}

The education system is a set of rules and conditions that preserve the society aspiration. By this definition, it offers what is needed by the community to reach the economic targets (growth, dexterity of work, technology mastering...), the social objectives (harmony, organization, patriotism) and the discipline goals (virtues, ethics, self-respect, selfconfidence). In doing so, the system builds curriculums and conceives contingent syllables to go hand in hand with the economic and social requirements of the people. This issue reflects the importance of respecting both the current development level of the country and the social background of the community. In this context, the policy purposes incline to discover the secrets of this causation between the education system establishments and the realization of the society welfare. The causation tends to explore the intermediate channels by which the education impacts the power (strength or weakness) of the targets realization.

\section{Intermediate Targets and the Power of Impact}

The intermediate target influenced by the education system can be divided into three units: the behavior target, the harmony target and the cohesion target.

\subsection{The Behavior Target}

The education system exercises an effect on society through the individuals by the specific and different influences on their traits and personalities. The personal strategy responds and affects the inconsistency of life situations. If the system is not conform with both the cognitive and personal traits of the individuals, it will more probable for a disturbance in personality structure to appear and then the system will deviates from the pathway of building the first component of the social welfare denoted by the compatibility of the personality trait to social targets.

\subsection{The Harmony Target}

This target means that the education system must ensure the conformity between three aspects: operational aspect (the different syllabuses of the education system), communicational aspect (the readiness creation to the public supposed to inhale the topics and subjects of the system and building an inner framework for realizing the goals of the education system); and environmental aspect (the societal and economic targets of the education system). This tridimensional view is figured out by the following: 


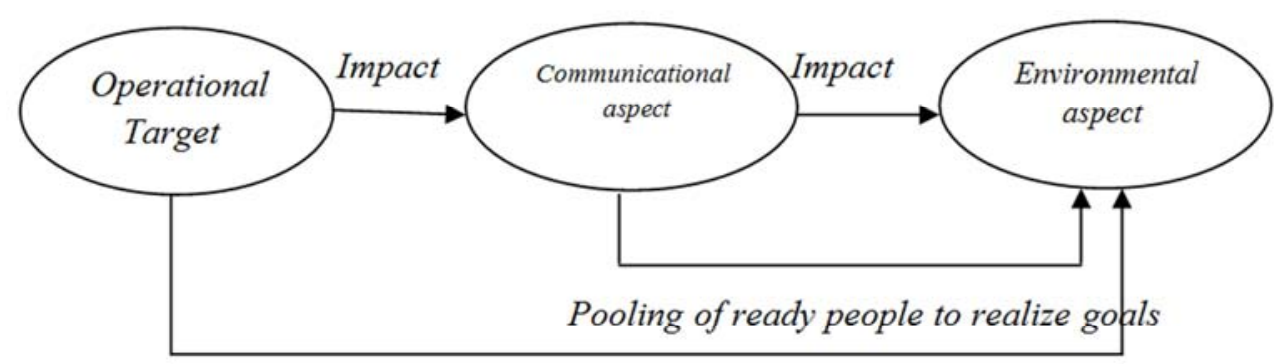

Creation an intellectual capacity and awareness

Source: the researcher

Figure 1. The channels of the harmony target.

\subsection{The Cohesion Target}

The third target indicates that the proposed education system is more able than all the other systems to reduce the disturbances between inner capacities and the outer ones. The former means the power of the individuals to adapt their cognitive faculties with their proper environment (management of the personality divergence from its proper environment and tradition). The outer capacity characterizes the ability of the environment to have a specific effect on the individual cognitive structure (management of the environment in favor of personality wants and by respect of its conditions). The following schema shows the comovement between the inner and the outer capacities under the cohesion target:

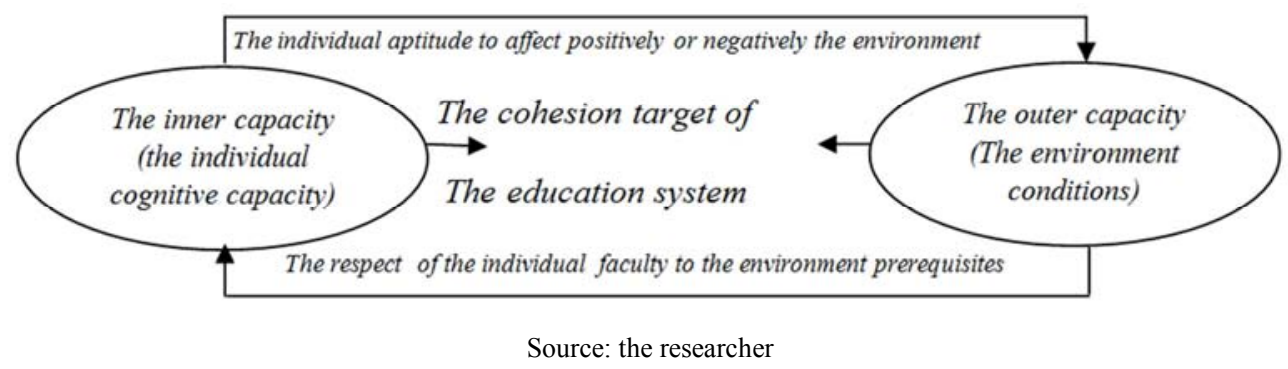

Figure 2. The components of the cohesion target.

\section{Measures of the Education System}

The measurement process of the education system is typically based on two complementary approaches: the quality approach and the quantity approach.

\subsection{The Quality Approach}

This method of testing refers to analyze the content of the education system curriculums. The purpose of this operation is to measure the magnitude of the compatibility between the scientific package of the system and the aspirations of the society in general. The issue raised in this context is to find the appropriate way of the content evaluation: is it by adopting a gradual scrutiny of the content according to the level requirements and the long term society aspirations? Or is it a general study of the content based on the institutional and formal targets without taking care of the economic efficiency considerations?

The state of the art shows the simultaneity in using the two approaches. This means that the analysis follows the economic and the institutional approaches at the same time. The components of the economic efficiency method are: the level of the learner and the intents of the society via the content of the curriculum. In addition to that, the analysis focuses on building a network of adequacy and feasibility: does the learner have a mental capacity and moral faculties to absorb, understand, comprehend and analyze the issues raised in his program? If so, how can this learner transform this scientific background into a real and palpable fact?

The problematic of network building of the level and the goals is surrendered by the interaction of three criteria: the readiness of the learner (Is the learner ready to understand what is presented to him?), the personality of the learner (Is the learner confident in himself and confident in what he is doing or just a sluggish and a person of a big lost confidence?) and the remaining criterion is about the power of the mental faculty of the learner (does the learner understand quickly or slowly? Is it just by the first explanation that the learner gets the idea or by repeating?

These questions find their answers by the nexus educationsociety network as follow:

The scores of the readiness are coined by:

AAA (Ready to learn and understand the issues)

AAB (Ready to learn but the learner is irritated to Understand hard issues (lack of understanding confidence)

ABB (Ready to learn but the learner faces difficulties in 
understanding (lack of understanding capability)

The scores of the personality are termed by:

A (Strong and optimist personality in what it is doing)

B (perplexed and annoyed personality which does not precise its goals)

The next step is to match each score of the readiness block by its counterpart in the personality scores as the diagram shows:

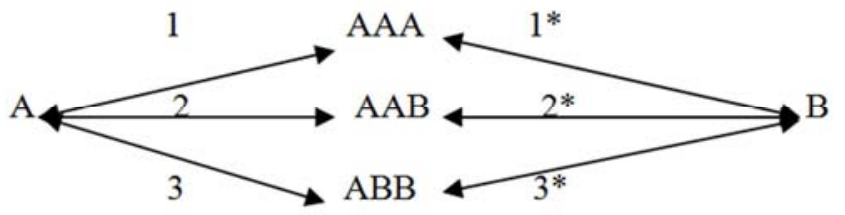

Source: the researcher

Figure 3. Personality and readiness nexus.

\subsection{The Efficiency Approach}

The efficiency approach tends to measure the impact of the education efficiency to build the desired persona able to take the economic and the social responsibilities of the country. In this context, the education curriculum should be aligned with the realization of three objectives: the psychological perspectives (what are the requirements of the desired personality both in terms of the economic and social situation of the context under study-contingency approach of education. The second objective is linked to the framework or the environment in which the education curriculum is adopted. In this context, the convenience condition between the developmental level of the institution and the aspirations of the education curriculum should to be checked in a way that ensures further the appropriate building of skills and competencies. The third objective is related to the general environment and its prerequisites from the education system. Here the following points are outlined and analyzed simultaneously with the design and the adoption of any education system: the economic situation of the environment (actual analysis), the prospective situation (the future goals of the economic and social programs) and the respect of the legacy and the culture of the society. The last objective is conceived and used throughout the system of the efficiency approach as a feedback to strengthen the position of the education in the society and to stretch the positive impacts of the education on the context in which it is applied. Additionally, the network of the efficiency system takes into account both the micro and the macro visions of the education system and the society. The former is interested by improving the intellectual capital of the individuals and the latter looks at the development of all the variables that conduct this improvement beyond the education per se. The network of the efficiency approach is figured out by the following diagram:

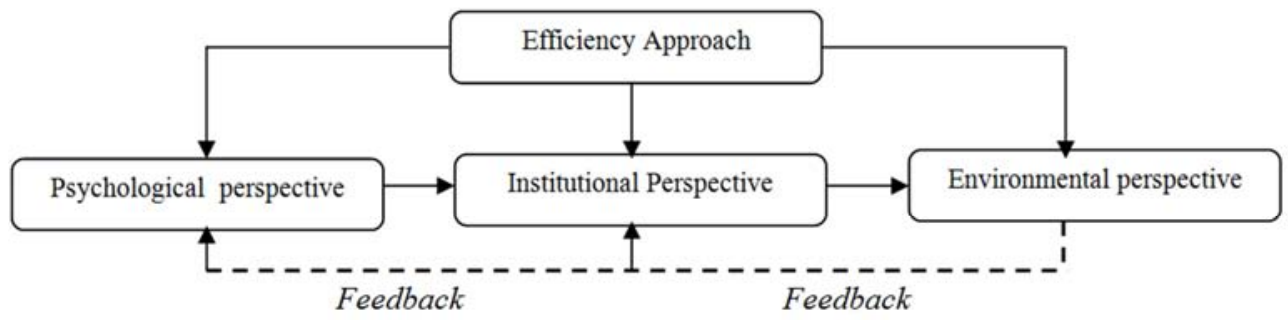

Source: the researcher

Figure 4. The efficiency network.

\section{The Efficiency Measures and the Social Welfare}

The aims of the major researches that have been presented to analyze the role of education in promoting the social and economic welfare were revolving around the question of the extent to which the education system in general affects the social and the economic context of the society. This issue is presented via various trials of measuring the educational efficiency and examining the pathways of the impact. Some studies focus on the number of the years spent by the individuals in schools as a proxy of the intellectual and educational advancement of the society. Others emphasize the need to compute the number of the individuals having school degrees as an indicator of the integrity and the harmony of the education system with the development requirements of the society. In addition to this, the analyses that looked at the effects of the education on the economic growth took the education expenditure incurred by the government or the assigned authorities to show the interest of the country in the improvement of the intellectual components of the individuals. The higher the funds spent to ameliorate the level of the education system, the higher the efficiency of the latter will be. These technical attempts to analyze the efficiency of the education system are coordinated to reveal the appropriate and suitable measure that shows the real contribution of the education system in creating the intellectual background necessary for the development and the prosperity. Consider the following developed Cobb-Douglas Model:

$Y=L^{\alpha} . K^{\beta} . T^{\gamma}$ in which $L, K, T$ denote labor, capital and technology respectively; $\alpha, \beta, \gamma$ indicate the parameters of the exploitation efficiency of each component of the above model. This equation demonstrates the contribution level and the extent of the rational exploitation 
in creating the welfare and economic growth revealed by the variable. In the context of the education system, the developed Cobb-Douglas model formula is illustrated by the following:

$$
Y=L^{\alpha} \cdot K^{\beta} \cdot E^{\varphi} \cdot T^{\gamma}
$$

where $E$ indicates the education system designed ad applied in a specific district or location, $\varphi$ means the parameter of the efficiency of the education system in creating welfare. This developed model takes into account the importance of knowledge as a way to exploit, use and benefit cleverly from the technology. Thus, the equation (1) is formulated as follow:

$$
Y=L^{\alpha} \cdot K^{\beta} \cdot E\left(T^{\varphi+\gamma}\right)
$$

In which the technology $T$ becomes an endogenous variable in the model showing the applied process of the education system; and the efficiency of the latter in this case is measured by both the efficiency of the system per se (the
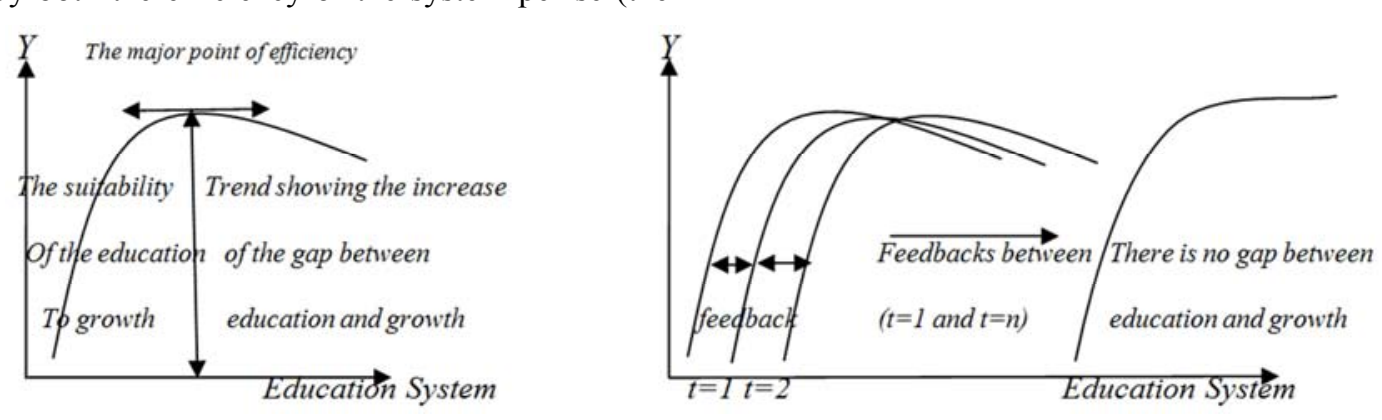

Source: the researcher

Figure 5. The efficiency of the education system and the growth.

\section{Conclusion}

This paper tries to shed light on the mechanisms through which the education system impacts the environment and the society that adopts its principles. In this respect, there is a correlation whether positive or negative between the system itself and the situation of the environment in which it is applied. Whatever the case, any educational system serves the objectives that are linked to the humans (the consolidation and the improvement of the intellectual capital of the individuals), as well as the society (the safeguard of the legacy and the cultural background of the society) and the environment (the respect of the environment conditions). Thus, the efficiency of the education system in creating and increasing the social welfare depends to a large extent on the respect and the continual strive to achieve the goals cited above.

\section{References}

[1] Alice M. Rivlin. (1973), Measuring Performance in Education, National Bureau of Economic Research: 411-437. efficiency of the system design $\varphi$ ) and the efficiency of the system exploitation and benefits $\gamma$ (to what extent this system is useful to master the technology wanted?). Therefore, the practical efficiency of the education system in creating the welfare and increasing the growth is found by the first partial derivative of the equation (2) to the education model as follow:

$$
\frac{\partial E\left(\varphi^{\varphi+\gamma}\right)}{\partial Y}=0: \text { this point shows the major capacity of the }
$$

education benefits that it can offer to the society in terms of creating the desired intellectual capital of the individuals and increasing the economic welfare accordingly. The point of the maximum efficiency is used interchangeably both as a feedback to enhance the position of capital and labor of the above equation (technical feedback) and a parameter of evaluating the current state of the education system to propose the further corrective measures (systemic feedback). The feedback is shown by the following diagram: 
[9] Jaap Scheerens. (2014), Effectiveness of Time Investment in Education: Insights from a Review and Meta-Analysis, Springer Cham Heidelberg New York Dordrecht London.

[10] Jana Strakova. (2007), The Impact of the Structure of the Education System on the Development of Educational Inequalities in the Czech Republic, Czech Sociological Review 43 (3): 589-610.

[11] John C. Dewdney. (1988), Geography in the Education System, Area 20 (1): 75-78.

[12] Justine Mercer, Bernard Barker, Richard Bird. (2010), Human Resource Management in Education: Contexts, Themes and Impact, Taylor \& Francis e-Library.

[13] Klaus Hurrelmann, Katharina Rathmann and Julian Kickbusch. (2015), Welfare and Education, International Encyclopedia of the Social \& Behavioral Sciences: 481-490.

[14] Laudan Aron and Pamela Loprest. (2012), Disability and the Education System, The Futre of Children 22 (1): 97-122.

[15] Lubov Ivankina and Tatjana Latygovskaya. (2015), Modern Social Welfare in the Light of Sustainability Model, ProcediaSocial and Behavioral Sciences 166: 111-115.
[16] Peter Hodgkinson. (1991), Educational Change: A Model for Its Analysis, British Journal of Sociology of Education 12 (2): 203-222.

[17] Philip G. Altbach. (2001), Measuring Academic Progress: the Course Credit System in American Higher Education, Higher Education Policy 14: 37-44.

[18] Prakob Koraneekij and Jintavee Khlaisang. (2015), Development of E-Portfolio Management System Towards Thai Qualification Framwork for Higher Education, ProcediaSocial and Behavioral Sciences 174: 1420-1427.

[19] Rachel Elboim-Dror. (1970), Some Characteristics of the Education Policy of the Formation System, Policy Sciences 1 (2): 231-253.

[20] Robert L. Ebel and David A. Frisbie. (1991), Essentials of Educational Measurement, Fifth Edition, Prentice Hall of India.

[21] Thomas Owen Eisemon and Lauritz Holm-Nielsen. (1995), Reforming Higher Education Systems: Some Lessons to Guide Policy Implementation, Higher Education 29 (4): 405420. 